\title{
Intestinal Schistosomiasis and the Associated Transmission Factors in Pre-School Aged Children in Villages Surrounding Lake Rweru in Bugesera District, Rwanda
}

\author{
Elias Niyituma ${ }^{1 *}$, Kato J. Njunwa², Amos K. Mbugua ${ }^{3}$, Corine Karema ${ }^{4}$, Irenée Umulisa ${ }^{4}$, and Gerald M. Mkoji ${ }^{5}$ \\ ${ }^{1}$ Institute of Tropical Medicine and Infectious Diseases (ITROMID), Jomo Kenyatta University of Agriculture and Technology, P.O. Box 62000- \\ 00200, Nairobi, Kenya \\ ${ }^{2}$ College of Medicine and Health Sciences/ University of Rwanda (CMHS/UR) PO Box 3286 Kigali, Rwanda \\ ${ }^{3}$ Department of Medical Laboratory, Jomo Kenyatta University of Agriculture and Technology (JKUAT), P.O. Box 62000-00200, Nairobi, Kenya \\ ${ }^{4}$ Malaria and other parasitic diseases Division, Rwanda Biomedical Center (RBC), PO Box 7162 Kigali, Rwanda \\ ${ }^{5}$ Centre for Biotechnology Research and Development, Kenya Medical Research Institute (KEMRI), PO Box 54840-00200, Nairobi, Kenya
}

\begin{abstract}
Background: Schistosomiasis is a waterborne snail-transmitted parasitic disease and is a major public health problem in sub-Saharan Africa, affecting populations living where water supply and sanitation are poor and inadequate. Pre-school aged children (PSAC) have often been ignored in disease control and prevention programs, as a result very little information is available on the prevalence or intensity of schistosomiasis in this age group.

Objective: This study was conducted to determine the prevalenceand intensity of intestinal schistosomiasis among PSAC, and determine factors associated with infection transmission in PSAC in villages surrounding Lake Rweru in Bugesera District, Rwanda.

Methods: This was a cross-sectional study involving 256 PSAC aged 12-59 months. Double Kato-Katz (KK) stool smears and the point of care circulating cathodic antigen (CCA) test were used to diagnoseS. mansoni in stool and urine samples, respectively. A questionnaire in the local language (Kinyarwanda) was administered to parents/guardians of the PSAC to determine factors associated with schistosomiasis transmission in the area.

Results: Based on the KK stool smears, no S. mansoni infection was found in any of the PSAC identified. However, using the point of care CCA test, $16.9 \%$ of the PSAC tested positive, when trace was considered as positive. The information collected on questionnaire showed a significant association between infection with $S$. mansoni(based on the CCA test) and visits to the lake especially, when the children accompanied their parents/guardians, or older children $(P<0.000)$.

Conclusion: The prevalence of $S$. mansoni in the study population was low on CCA test and the infection was associated with going to the lake by the children when they accompanied their parents/guardians or older siblings. The children who go to the lake should prevent direct contact with lake's water. These results call for the need to consider including a point of care screening tool for $S$. mansoni infections among preschool children as well as a prevention program targeting this age group in the study area.
\end{abstract}

Keywords: Intestinal schistosomiasis prevalence, Pre-school children, Rwanda

\section{Background}

Schistosomiasis is a waterborne snail-transmitted parasitic diseases and a major public health problem in sub-Saharan Africa, mostly, affecting populations living in low-resource countries where, water supply and sanitation are poor and inadequate (Chitsulo et al., 2000). It is estimated that more than 200 million people worldwide, mostly in tropical and subtropical countries are infected (Gryseels et al., 2006; King et al,. 2005; Sady et al,. 2013). It is difficult to accurately estimate the disease burden due to schistosomiasis, but recent work suggests that a loss of 3-70 million disabilityadjusted life years (DALYs) is attributed to the disease (King et al., 2005). Significant reduction of infection and morbidity has been achieved in some countries of Africa through global efforts to eliminate schistosomiasis and other neglected tropical diseases (NTDs) by deworming (Kabatereine et al., 2007).

In Rwanda several studies have been done on intestinal schistosomiasis especially in school children, and the prevalence in the country ranges from 0 to $69.5 \%$, but no cases of urinary schistosomiasis have been reported so far(Rwanda Ministry of Health, 2008; Mupfasoni et al.,
2009; Ruberanziza et al., 2015).

Formanyyears, itwas generally believed thatschistosomiasis prevalence and intensity curves show peaks in school aged children (SAC) aged 6-15 years, and this age group was often used in providing an index for assessing community infection prevalence. Accordingly, epidemiological studies and control interventions on schistosomiasis have frequently directed towards school-aged children by regular administration of Praziquantel(Kabatereine et al., 2007).

Because of lower frequency of active water contact of pre-school-aged children (PSAC) $[<6$ years] compared to school aged children (SAC) and the development of an acquired protective immunity against schistosomiasis in adolescents and adults ( $\geq 16$ years), PSAC have often been ignored in disease control and prevention programs (Verani et al., 2011). As a result very little information is available on the prevalence or intensity of schistosomiasis in infants and PSAC in much of the endemic areas of the world including Rwanda. There is emerging evidence that, however, infants and PSAC are also infected in moderate to high schistosomiasis transmission areas.(Odogwu et al., 2006; Opara et al., 2007). 
The detection of $S$. mansoni eggs in stool samples using Kato-Katz (KK) smears by microscopy is the most commonly used method, and its benefits include high specificity, low cost, and simplicity. However, the sensitivity of this method is low particularly in areas of low endemicity, and lowinfection intensities (e.g. in young children), and may be affected by day to day variability in the rate of egg excretion (Barreto et al., 1978; Shane et al., 2011; Teesdale et al., 1985).

Immunodiagnosis, on the other hand, is generally more sensitive than examination of stool samples, particularly in low transmission areas where infection intensities are light (Shane et al., 2011). Studies done in Uganda and Kenya to assess the Circulating Cathodic Antigen (CCA) urine dipstick test and thePoint of Care-Circulating Cathodic Antigen (POC-CCA) cassette test in PSAC, recommended these rapid tests as useful tools for the detection of $S$. mansoni in that age group (Sousa-Figueiredo et al., 2013; Verani et al., 2011). In one study conducted in Ivory Coast whereS. mansonis common among school-aged children (SAC), a single POC-CCA cassette test was shown to have similar sensitivity as triplicate KK thick smears (Coulibaly et al., 2011).

However, many studies have shown that day-to-day fluctuationsoccur in S. mansoni CCA test scores and in egg counts in KK smears, and therefore, it is recommended that a collection of several samples from individuals is necessary on consecutive days to increase the sensitivity of these methods (Coulibaly et al., 2013; Degarege et al., 2014; Sousa-Figueiredo et al., 2013).

But this may have some limitations like cost and obtaining stool specimens from individuals on different days which would be challenging (Knopp et al., 2008), so it is easier to use double KK smears for single stool sample and even a single urine-CCA cassette test would be enough for mapping and screening of $S$. mansoni infection at a reasonable cost (Degarege et al., 2014).

As the degree of exposure and intensity of infection increases, it is necessary to document the prevalence and intensity of infection in PSAC in schistosomiasis endemic areas so that they can benefit from large scale disease control programs.

The aim of this study was to determine the prevalence, intensity of $S$. mansoni infection and the factors associated with intestinal schistosomiasis transmission in preschool-aged children in areas surrounding Lake Rweru in Bugesera district using both $\mathrm{KK}$ as specific test and POCCCA cassette test as sensitive test.

\section{Method and materials Study area}

The Lake Rweru is located in the South-East of Rwanda (Rweru sector in Bugesera district), at an altitude of $1350 \mathrm{~m}$. The total surface area of Lake Rweru covers some $100 \mathrm{~km} 2$, of which $20 \%$ is in Rwanda and the remaining lie in Burundi. The mean depth is around $2.1 \mathrm{~m}$ with a maximum of $3.9 \mathrm{~m}$
(Ruberanziza et al., 2010). Compared to other regions of the country, Bugesera's climate is dry with a temperature varying between $20^{\circ} \mathrm{C}$ and $30^{\circ} \mathrm{C}$ with an average ranging between 26 and $29^{\circ} \mathrm{C}$. The district has two dry periods and two rainy periods; a short dry season (January to midMarch), long rainy season (mid- March to June), long dry season (mid-June to September), a short rainy season (midOctober to December). This climate influences agriculture in Bugesera. About water and sanitation in this district, a big proportion still use unprotected water sources like rivers and lakes $(27 \%)$ and $7.9 \%$ households don't have toilet facilities (Republic of Rwanda, 2012).

\section{Study design and population}

This was a cross sectional study of 256 randomly selected PSAC aged 12-59 months from 10 villages surrounding Lake Rweru in Bugesera district, Rwanda. These PSAC had been living in the study area at least 3 months before the beginning of the study.

\section{Data collection \\ Questionnaire}

A structured questionnaire was administered to the enrolled children's parents/guardians, to collect the sociodemographic data of the parents/guardians of study participant, hygiene, sanitation, and lake's water contact of study participant

\section{Laboratory procedure}

Single urine and stool samples were collected from enrolled children. CCA tests (Rapid Medical Diagnostics; Pretoria, South Africa) were conducted according to the manufacturer's instructions on single urine samples. The CCA results were read after 20 minutes after adding the buffer solution. CCA results were graded as negative, trace, 1+, 2+, and 3+. For stool samples double KK thick smears were prepared for each sample by using template which can hold $41.7 \mathrm{~g}$ of stool, the smears were left 24 hours for clearing before examination for $S$. mansoni eggs. $\mathrm{KK}$ and slides were examined at Nzangwa Health center for Schistosoma and STH eggs by light microscopy. A and $B$ smears were read by different technicians. After the survey, a $10 \%$ of slides were randomly selected and sent to National reference laboratory division/ Rwanda Biomedical Center for control.

\section{Data analysis}

Double data entry were performed in Microsoft Excel 2010 spreadsheet, and checked for entry errors. The STATA version 11 (Stata Corp.; College Station, Texas) was used in analysis. The mean and standard deviation of age variable were described and categorized in age groups: 12-24, 25-36, 37-48, and 49-59 months. Binary variables were compared using the Chi- square test $\left(\square^{2}\right)$ or the Fisher exact test, where appropriate. Socio-demographic, hygiene, sanitation, and lake's water contact of study participant to the Schistosomiasis were assessed using logistic regression.

\section{Ethical consideration}

The study was approved by Rwanda National Ethic Committee (RNEC) No.331/RNEC/2015 and Malaria \& OPDD-RBC. Before starting the study, meetings were 
held at village's level with parents whom have pre-school aged children to describe the purpose of the study, the procedures to be followed, and the risks and benefits to the participation. Written informed consent was obtained from the parents/guardians of children before their enrolment into the study. The study has minimal risks to the participants, because the samples (stool and urine) that were used are obtained in normal life processes. Praziquantel and albendazole at the recommended doses were administered to the infected children under the supervision of a qualified clinician. Information obtained on the questionnaire was treated in confidential way and the records were stored in a locked cabinet and data were entered in a password protected file in a computer.

\section{Results}

\section{Demographic characteristics of the study children}

A total of 251 PSAC living in 10 villages on the shoreline of lake Rweru aged 12 to 59 months with a mean of age $35.3 \pm 13$ months $(95 \% \mathrm{Cl}=12,13.8)$ participated in this study, the compliance was $98 \%$ and $96.8 \%$ for stool and urine submission respectively. Among these children $51.8 \%$ were males and $48.2 \%$ were females. Participants were distributed in villages as following: $19.5 \%, 17.1 \%, 12.7 \%$, $11.2 \%, 9.2 \%, 7.6 \%, 7.6 \%, 6.4 \%, 5.2 \%$ and $3.6 \%$ for Ruzo, Kigina, Mugina, Sharita, Rusenyi, Nyiragiseke, Karizinge, Mujwiri, Gasasa, and Rukira respectively. Table 1 and table 2 show the general characteristics of participants

Table 1. Demographic characteristics of the 251 study pre-school children from villages surrounding Lake Rweru, Bugesera district in Rwanda

\begin{tabular}{|c|c|c|c|c|c|c|}
\hline & & & hildren $\mathrm{G}$ & ender & & \\
\hline & & Female & & Male & & \\
\hline $\begin{array}{l}\text { Age groups } \\
\text { (months) }\end{array}$ & Number & - Percentage & Number & Percentage & Mean & S.D \\
\hline $12-24$ & 32 & $12.7 \%$ & 32 & $12.7 \%$ & & \\
\hline $25-36$ & 34 & $13.5 \%$ & 33 & $13.1 \%$ & & \\
\hline $37-48$ & 30 & $12.0 \%$ & 39 & $15.5 \%$ & & \\
\hline $49-59$ & 25 & $10.0 \%$ & 26 & $10.4 \%$ & & \\
\hline Total & 121 & $48.2 \%$ & 130 & $51.8 \%$ & 35.37 & 13 \\
\hline
\end{tabular}

Table 2. Distribution of the pre-school children enrolled into the study and categorized according to sex and village

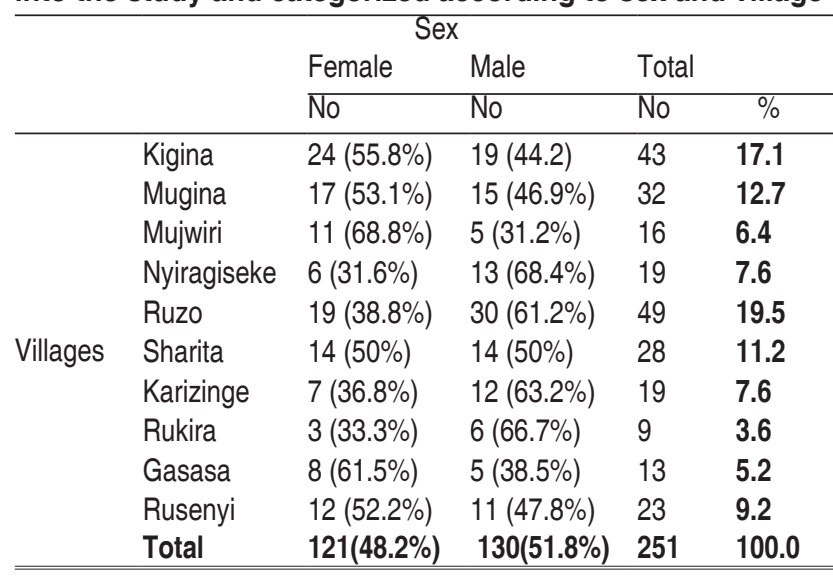

Intestinal schistosomiasis caused by $S$. mansoni

In a total of 251 pre-school aged children examined based on $\mathrm{KK}$ technique, none was found to be positive for $S$. mansoni.

Prevalence of S. mansoni based on CCA cassette test The prevalence of $S$. mansoni based on CCA cassette test considering trace as positive (CCA t+), 42/248, 16.9\% (95\% Cl: 12.6-21.8) of participants were infected with $S$. mansoni. According to the sex, the prevalence in male children was $19.4 \%$ and in the female children the prevalence was $14.3 \%$, this difference was not statistically significance ( $\left.X^{2}=1.14, P=0.28\right)$, according to age group the prevalence of S. mansoni was $19.4 \%, 19.7 \%, 13 \%$, and $15.7 \%$ for 12-24, 25-36, 37-48, and 49-59 months respectively, the difference was not statistically significant (Fisher's exact test=1.45, $P=0.72$ ). When we consider the trace as negative (CCA t-), the prevalence of $S$. mansoni was $7 / 248$, $2.8 \%(95 \% \mathrm{Cl}: 0.8-4.8)$. The prevalence in male children was $3.1 \%$ while in female children was $2.5 \%$, the difference was not statistically significance $\left(X^{2}=0.76, P=1\right)$. According to age group of PSAC, the prevalence was $0.0 \%, 3.0 \%$, $4.3 \%$, and $3.9 \%$ for $12-24,25-36,37-48$, and $49-59$ months respectively, the difference was not statistically significant (Fisher's exact test $=2.89, P=0.5$ ). Figure 1 shows the prevalence of $S$. mansoni infection based on CCA cassette test in general whereas, Table 3 shows infection prevalence according to gender and age groups.

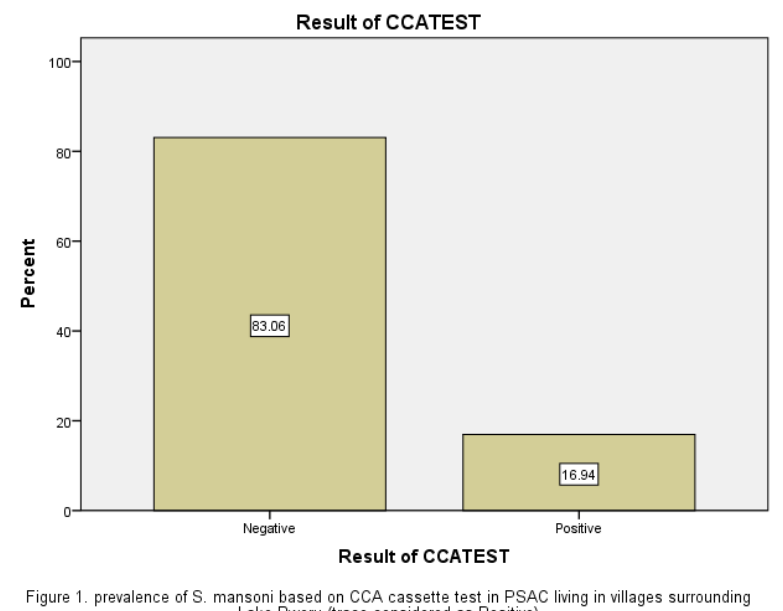
Figure 1. prevalence of $S$. mansoni based on CCA cassette test in PSAC living in villages surrounding
Lake Rweru (trace considered as Positive)

Table 3. Prevalence of S. mansoni based on CCA cassette test according to sex and age group of PSAC in villages surrounding Lake Rweru

\begin{tabular}{lccccc}
\hline \multicolumn{5}{c}{ CCA test results } \\
& Negative & Positive & Total & \multicolumn{2}{c}{$X^{2} P$-value } \\
\hline Sex & & & & & \\
$\quad$ Male & $104(80.4 \%)$ & $25(19.4 \%)$ & 129 & 1.14 & 0.28 \\
Female & $102(85.7 \%)$ & $17(14.3 \%)$ & 119 & & \\
Age group & & & & & \\
12-24 & $50(80.6 \%)$ & $12(19.4 \%)$ & 62 & 1.45 & 0.72 \\
$25-36$ & $53(80.3 \%)$ & $13(19.7 \%)$ & 66 & & \\
$37-48$ & $60(87 \%)$ & $9(13 \%)$ & 69 & & \\
$49-59$ & $43(84.3 \%)$ & $8(15.7 \%)$ & 51 & & \\
\hline
\end{tabular}




\section{Sanitation and lake's water contact habits}

$94.8 \%$ of surveyed children were living in household with the presence of toilet. $62.5 \%$ of children were defecating in the toilet while $35.1 \%$ were defecating around the house. $88.4 \%$ of the children had parents/guardian who use water from the lake as first choice of water use at home while only $4.4 \%$ use tap water, $81.3 \%$ of the study children use water from lake as first choice of water bathing. Approximately, $97 \%$ of the parents/guardians of PSAC reported that their children got frequently into contact with lake water. $79 \%$ of children were in contact with water from lake when bathing while $13.5 \%$ had contact when accompanying adults. Sanitation and lake's water contact habit is presented in table 4.

\section{Factors associated with $S$. mansoni infection in PSAC}

The association between $S$. mansoni infection and sanitation and lake's water contact habit by the children is presented in Table 5.
Although not significant ( $p>0.05$ ), Children living in household without toilet had roughly 2 times the odd to have $S$. mansoni infection compared to children who had toilet ( OR 2.16(0.46-10.12). Even though not significant ( $p>0.05$ ), children defecating around the house had 1.5 odds (OR 1.59 (0.69-3.61)) of having $S$. mansoni infection compared to those defecating in the toilet $(p>0.05)$. Although not significant ( $p>0.05$ ), children who had contact with lake had nearly 5 times the odds (OR $4.8(0.87-27.16)$ ) to have S. mansoni infection compared to those who did not have contact with lake ( $p>0.05)$.

Accompanying parents and older children by the PSAC to the lake was significantly associated with $S$. mansoni infection with 10 times the odd than other children $(p<0.000)$ as presented in Table 5.

Table 4. Sanitation and lake's water contact habit of studied PSAC

\begin{tabular}{lll}
\hline & Frequency & $95 \% \mathrm{Cl}$ \\
\hline Presence of toilet & $238(94.8 \%)$ & $91.6-97.5$ \\
Yes & $13(5.2 \%)$ & $2.5-8.4$ \\
No & & \\
Areas where the child defecates & $157(62.5 \%)$ & $56.7-68.8$ \\
$\quad$ Toilet & $88(35.1 \%)$ & $29.2-41.0$ \\
Around house & $6(2.4 \%)$ & $0.4-4.8$ \\
In bushes & & $2.1-7.2$ \\
First choice of the source of water used at home & $11(4.4 \%)$ & $2.0-6.8$ \\
Tap water & $10(4 \%)$ & $1.2-5.6$ \\
Stream & $8(3.2 \%)$ & $84.2-92.0$ \\
Pond & $222(88.4)$ & $3.2-9.0$ \\
Lake & $15(6 \%)$ & $4.8-12.0$ \\
First choice of the source of water used to bath child & $21(8.4 \%)$ & $2.0-7.0$ \\
Tap water & $11(4.4 \%)$ & $76.9-85.7$ \\
Stream & $204(81.3 \%)$ & \\
Pond & & $95.2-98.8$ \\
Lake & $244(97.2 \%)$ & $1.2-4.8$ \\
Contact with lake water & $7(2.8 \%)$ & $74.6-84.7$ \\
Yes & & $9.4-18.6$ \\
No & $195(79.9 \%)$ & $3.7-10.1$ \\
How & $33(13.5 \%)$ & \\
At home (bathing with lake water) & $16(6.6 \%)$ & \\
Accompany parent/older children to the lake & & \\
Goes him/herself to lake & & \\
\hline
\end{tabular}




\begin{tabular}{|c|c|c|c|c|c|}
\hline \multirow{2}{*}{\multicolumn{6}{|c|}{$\begin{array}{l}\text { Table } 5 . \text { The factors associated with th } \\
\text { schistosomiasis in PSAC in villages su } \\
\text { Rweru, Bugesera district }\end{array}$}} \\
\hline & & & & & \\
\hline Negative positive & Total & \multicolumn{2}{|c|}{$\mathrm{OR}(95 \% \mathrm{Cl})$} & \multicolumn{2}{|l|}{$P$-value } \\
\hline \multicolumn{6}{|l|}{ Toilet ownership? } \\
\hline Yes & $199(84.7)$ & $36(15.3)$ & 235 & & $<0.328$ \\
\hline No & $7(53.8)$ & $6(46.2)$ & 13 & $2.16(0.46-10.12)$ & \\
\hline \multicolumn{6}{|l|}{ Child defecates } \\
\hline In toilet & $134(85.9)$ & $22(14.1)$ & 156 & & $<0.467$ \\
\hline Around the house & $67(77.9)$ & $19(22.1)$ & 86 & $1.59(0.69-3.61)$ & \\
\hline In the bushes & $5(83.3)$ & $1(16.7)$ & 6 & $0.66(0.03-11.5)$ & \\
\hline \multicolumn{6}{|l|}{ Home using water } \\
\hline Tap water & $9(81.8)$ & $2(18.2)$ & 11 & & $<0.616$ \\
\hline Stream & $7(70)$ & $3(30)$ & 10 & $6.06(0.29-122.4)$ & \\
\hline Pond & $5(62.5)$ & $3(37.5)$ & 8 & $7.24(0.35-148.5)$ & \\
\hline Lake & $185(84.5)$ & $34(15.5)$ & 219 & $2.46(0.17-33.9)$ & \\
\hline \multicolumn{6}{|l|}{ Water used to bath child } \\
\hline Tap water & $10(66.7)$ & $5(33.3)$ & 15 & & $<0.604$ \\
\hline Stream & $20(95.2)$ & $1(4.8)$ & 21 & $0.13(0.009-1.81)$ & \\
\hline Pond & $9(81.8)$ & $2(18.2)$ & 11 & $0.89(0.09-8.18)$ & \\
\hline Lake & 167(83.1) & $34(16.9)$ & 201 & $0.67(0.14-3.15)$ & \\
\hline \multicolumn{6}{|c|}{ Child contact with lake's water } \\
\hline Yes & 202(84.6) & $39(15.4)$ & 241 & & $<0.065$ \\
\hline No & $4(57.1)$ & $3(42.9)$ & 7 & $4.86(0.87-27.16)$ & \\
\hline \multicolumn{6}{|l|}{ How } \\
\hline \multicolumn{5}{|l|}{ Use lake's water } & $<0.000$ \\
\hline to bath children & 172(89.6) & $20(10.4)$ & 192 & $0.11(0.04-0.27)$ & \\
\hline \multicolumn{6}{|l|}{ Child goes to the lake } \\
\hline her/himself & $15(93.8)$ & $1(6.2)$ & 16 & $0.06(0.007-0.56)$ & \\
\hline
\end{tabular}

\section{Discussion}

The aim of this study was to determine the prevalence and intensity of $S$. mansoni infection in pre-school aged children (PSAC) in an area located on the shores of Lake Rweru in Rwanda Eastern province, and considered endemic for intestinal schistosomiasis, and where infection intensity is categorized as moderate, and determine the factors associated with infection transmission among the PSAC. Intestinal schistosomiasis caused by $S$. mansonis endemic in Rwanda, especially around the lakes Ruhondo, Burera, Rweru, Kivu and on Nkombo Island (Hanotier and Gigase 1981; Mupfasoni et al., 2009; Ruberanziza et al., 2010; Ruberanziza et al., 2015), with data being available for school age children. Until now, virtually no information was available on the prevalence of $S$. mansoni among the PSAC. The present study conducted around Lake Rweru located in Rwanda Eastern provincewas a first attempt to obtain data on $S$. mansoni prevalence for this age group in Rwanda.

The fact that in the present studyno $S$. mansoni infection was detected among pre-school aged children in villages surrounding Lake Rweru in Bugesera district, Rwanda using the Kato-Katz procedure, and the fact that only about $17 \%$ of the PSAC tested positive with the urine CCA test when trace results were considered as positive, suggest that the prevalence of $S$. mansoni among this age group, in this particular area, may be too low to be of public health significance. It should be understood, however, that in this particular geographic area, S. mansoni among the school age children is within the moderate intensity range. It is recommended that data for this age group from other intestinal schistosomiasis endemic areas within Rwanda will be necessary, if the epidemiology of schistosomiasis and the pre-schoolage group is to be fully understood in this country.

Between the microscopy-based Kato-Katz procedure and the immune-diagnostic-based urine circulating cathodic antigen (POC- CCA) assay, it appears the latter is a more sensitive test, in terms of being able to detect even low level S. mansoni infection. With respect to sensitivity of the tests, the results from the present study are similar to those obtained from other studies done elsewhere, in which the two tests were also, compared (Adriko et al., 2014; Colley et al., 2013; Degarege et al., 2014; Mwinzi et al., 2015).

They do suggest the value of the urine CCA test in epidemiological studies of $S$. mansoni, particularly where infection prevalence is relatively low. In addition, the CCApositive results where Kato-Katz results were $S$. mansoni egg-negative among the PSAC, could also, suggest the presence of pre-patent immature infections (where the parasites are not at the stage of laying eggs). Alternatively, the eggs laid by the schistosomes in the infected children were below the detection levels of the Kato-Katz procedure (Adriko et al., 2014; Polman et al., 2000). It is also, possible that we were dealing with residual infections after chemotherapeutic interventions, which normally reduce the prevalence and increase in the number of infections of low intensity (Coulibaly et al., 2012; Knopp et al., 2011). Schistosomiasis control programs have been undertaken in Rweru area since 2010 (Rwanda Ministry of Health, 2010). The low prevalence of $S$. mansoni infection observed in the Rweru area, Rwanda among the PSAC in the current study differs from the results of similar studies conducted elsewhere, within the sub-Saharan region, and where prevalence with the Kato-Katz procedure was in the range 7-44\% and with the CCA test, was 40-80\% (Coulibaly et al., 2013; Odogwu et al., 2006; Ruganuza et al., 2015).

It is noted that majority of the study children in Rweru did not have direct contact with lake water, but contacted lake water at home during bathing. Schistosome cercariae present water are known to lose their infectivity with time, (Adenowo et al., 2015). Interestingly, there was a significant association between infection with $S$. mansoni and going to the lake by the PSAC especially when the children accompany their parents/guardians or older children to the lake. The similar findings have been reported in western Kenya and in Tanzania (Handzel et al., 2003; Ruganuza et al., 2015).

The present findings have a geographic limitation, cannot be generalized to the all endemic area in the country. This 
study didn't provide the malacology information in the area because of study design.

In conclusion the findings of this study have demonstrated that the prevalence of intestinal schistosomiasis in preschool aged children in village surrounding lake Rweru on Kato- Katz thick smears was $0 \%$, but $16.9 \%$ on the Point Of Care- Circulating Cathodic Antigen (POC-CCA) test, which indicates some level of the risk of $S$. mansoni infection among this age group. The control program should think to consider including them in Praziquantel mass drug administration campaigns. The results showed a significant association between infection with $S$. mansoni and going to the lake by the PSAC which indicates that the water may be contaminated with cercariae. Young children often accompany their parents/guardians or older children to the lakeshore.

We recommend assessing burden of schistosomiasis among this age group in other settings, to target this PSAC in national prevention and control program and the authority to provide safe and clean water to the population in this area. As there is insufficient information on $S$. mansoni infection among pre-school aged children in endemic area around Rwanda, further studies are needed to determine the public health significance of schistosomiasis in these areas.

\section{Acknowledgements and Funding}

Our well-expressed thanks go to families who accepted that their children participate in the study, together with their parents and guardians whogave consent for their children to participate in this study and make it a success. We acknowledge the generous support of the Executive Secretary of Rweru Sector and the Head of Nzangwa Health Center for permission to conduct this study and for allowing access to laboratory facility for this research. We sincerely thank Mr. Tharcisse MUNYANEZA and Dr. Eugene RUBERANZIZA for generously providing the materials used for field work during this study. This research received financial support from Rwanda Education Board which we acknowledge gratefully.

\section{Conflict of interests}

The authors declare that they have no competing interests

\section{Authors' contributions}

EN, GMM, AKM, KNN were involved in the study design. EN carried out data collection, analysis and manuscript development. GMM, AKM, KNN, IU, CK critically reviewed the manuscript and results interpretation. All authors read and approved the final manuscript.

\section{References}

Adenowo, A., Oyinloye, B., Ogunyinka, B., \& Kappo, A. (2015). Impact of human schistosomiasis in subSaharan Africa. Brazilian Journal of Infectious Diseases, 19(2), 196-205. http://doi.org/10.1016/j. bjid.2014.11.004

Adriko, M., Standley, C. J., Tinkitina, B., Tukahebwa, E. M., Fenwick, A., Fleming, F. M., ... Kabatereine, N. B. (2014). Evaluation of circulating cathodic antigen (CCA) urine-cassette assay as a survey tool for Schistosoma mansoni in different transmission settings within Bugiri District, Uganda. Acta Tropica, 136(1), 50-57. http://doi.org/10.1016/j. actatropica.2014.04.001

Barreto, M. L., Franca Silva, J. T., Mott, K. E., \& Lehman, J. S. (1978). Stability of faecal egg excretion in Schistosoma mansoni infection. Transactions of the Royal Society of Tropical Medicine and Hygiene, 72(2), 181-187. http://doi.org/10.1016/00359203(78)90056-1

Chitsulo, L., Engels, D., Montresor, A., \& Savioli, L. (2000). The global status of schistosomiasis and its control. Acta Tropica, 77(1), 41-51. http://doi.org/10.1016/ S0001-706X(00)00122-4

Colley, D. G., Binder, S., Campbell, C., King, C. H., Tchuent??, L. A. T., N'Goran, E. K., Rathbun, S. (2013). A five-country evaluation of a point-of-care circulating cathodic antigen urine assay for the prevalence of Schistosoma mansoni. American Journal of Tropical Medicine and Hygiene, 88(3), 426-432. http://doi.org/10.4269/ajtmh.12-0639

Coulibaly, J. T., Knopp, S., N'Guessan, N. A., Silué, K. D., Fürst, T., Lohourignon, L. K., Utzinger, J. (2011). Accuracy of urine circulating cathodic antigen (CCA) test for Schistosoma mansoni diagnosis in different settings of Côte d'Ivoire. PLoS Neglected Tropical Diseases, 5(11). http://doi.org/10.1371/journal. pntd.0001384

Coulibaly, J. T., N'Gbesso, Y. K., Knopp, S., Keiser, J., N'Goran, E. K., \& Utzinger, J. (2012). Efficacy and Safety of Praziquantel in Preschool-Aged Children in an Area Co-Endemic for Schistosoma mansoni and S. haematobium. PLoS Neglected Tropical Diseases, 6(12). http://doi.org/10.1371/journal.pntd.0001917

Coulibaly, J. T., N'Gbesso, Y. K., Knopp, S., N'Guessan, N. A., Silu??, K. D., van Dam, G. J., Utzinger, J. (2013). Accuracy of Urine Circulating Cathodic Antigen Test for the Diagnosis of Schistosoma mansoni in Preschool-Aged Children before and after Treatment. PLoS Neglected Tropical Diseases, 7(3). http://doi. org/10.1371/journal.pntd.0002109

Degarege, A., Legesse, M., Medhin, G., Teklehaymanot, T., \& Erko, B. (2014). Day-to-day fluctuation of point-ofcare circulating cathodic antigen test scores and faecal egg counts in children infected with Schistosoma mansoni in Ethiopia. BMC Infectious Diseases, 14(1), 210. http://doi.org/10.1186/1471-2334-14-210

Gryseels Bruno, Polman Katja, Jan Clerinx, L. K. (2006). Human Schistosomiasis. Lancet, 43(4-5), 323. http:// doi.org/10.1016/S0140-6736(06)69440-3

Handzel, T., Karanja, D. M., Addiss, D. G., Hightower, A. W., Rosen, D. H., Colley, D. G., Secor, W. E. (2003). Geographic distribution of schistosomiasis and soil- 
transmitted helminths in Western Kenya: implications for anthelminthic mass treatment. The American Journal of Tropical Medicine and Hygiene, 69(3), 318-323.

Hanotier J \& Gigase PL. (1981). Note on a New Focus of Schistosomiasis (S. Mansoni) in Rwanda. Ann. Soc. Belge Med. Trop.

Kabatereine, N. B., Brooker, S., Koukounari, A., Kazibwe, F., Tukahebwa, E. M., Fleming, F. M., Fenwick, A. (2007). Impact of a national helminth control programme on infection and morbidity in Ugandan schoolchildren. Bulletin of the World Health Organization, 85(2), 9199. http://doi.org/10.2471/BLT.06.030353

King, C. H., Dickman, K., \& Tisch, D. J. (2005). Reassessment of the cost of chronic helmintic infection: A metaanalysis of disability-related outcomes in endemic schistosomiasis. Lancet, 365(9470), 1561-1569. http://doi.org/10.1016/S0140-6736(05)66457-4

Knopp, S., Mgeni, A. F., Khamis, I. S., Steinmann, P., Stothard, J. R., Rollinson, D., Utzinger, J. (2008). Diagnosis of soil-transmitted helminths in the era of preventive chemotherapy: Effect of multiple stool sampling and use of different diagnostic techniques. PLoS Neglected Tropical Diseases, 2(11). http://doi. org/10.1371/journal.pntd.0000331

Knopp, S., Speich, B., Hattendorf, J., Rinaldi, L., Mohammed, K. A., Khamis, I. S., Utzinger, J. (2011). Diagnostic accuracy of kato-katz and FLOTAC for assessing anthelmintic drug efficacy. PLoS Neglected Tropical Diseases, 5(4). http://doi.org/10.1371/journal. pntd.0001036

Mupfasoni, D., Karibushi, B., Koukounari, A., Ruberanziza, E., Kaberuka, T., Kramer, M. H., Fenwick, A. (2009). Polyparasite Helminth Infections and Their Association to Anaemia and Undernutrition in Northern Rwanda. PLoS Negl Trop Dis, 3(9), e517. http://doi.org/10.1371/journal.pntd.0000517

Mwinzi, P. N. M., Kittur, N., Ochola, E., Cooper, P. J., Campbell, C. H., King, C. H., \& Colley, D. G. (2015). Additional Evaluation of the Point-of-Contact Circulating Cathodic Antigen Assay for Schistosoma mansoni Infection. Frontiers in Public Health, 3(March), 48. http://doi.org/10.3389/fpubh.2015.00048

Odogwu, S. E., Ramamurthy, N. K., Kabatereine, N. B., Kazibwe, F., Tukahebwa, E., Webster, J. P., ... Stothard, J. R. (2006). Schistosoma mansoni in infants (aged $<3$ years) along the Ugandan shoreline of Lake Victoria. Annals of Tropical Medicine and Parasitology, 100(4), 315-326. http://doi. org/10.1179/136485906X105552

Polman, K., Diakhate, M. M., Engels, D., Nahimana, S., Van Dam, G. J., Ferreira, S. T. M., Gryseels, B. (2000). Specificity of circulating antigen detection for schistosomiasis mansoni in Senegal and Burundi. Tropical Medicine and International Health, 5(8), 534537. http://doi.org/10.1046/j.1365-3156.2000.00600.x

Republic of Rwanda. (2012). EIVC 3 (Enquête Intégrale sur les Conditions de Vie des Ménages (Integrated
Household Living Conditions Survey)) district profile: East-Bugesera. Kigali.

Ruberanziza, E., Kabera, M., Ortu, G., Kanobana, K., Mupfasoni, D., Ruxin, J., Polman, K. (2015). Nkombo Island: The most important Schistosomiasis mansoni focus in Rwanda. American Journal of Life Sciences, 3(1), 27-31. http://doi.org/10.11648/j. ajls.20150301.16

Ruberanziza, E., Mupfasoni, D., Karibushi, B., Kabera, M., Karema, C., Nyatanyi, T., Ruxin, J. (2010). a Recent Update of Schistomiasis Mansoni Endemicity. Rwanda Medical Journal, 68(4), 6-9.

Ruganuza, D. M., Mazigo, H. D., Waihenya, R., Morona, D., \& Mkoji, G. M. (2015). Schistosoma mansoni among pre-school children in Musozi village, Ukerewe Island, North-Western-Tanzania: prevalence and associated risk factors. Parasites \& Vectors, 8, 377. http://doi. org/10.1186/s13071-015-0997-9

Rwanda Ministry of health. (2008). National prevalence survey on soil-transmitted helminths in school-aged children. Kigali.

Rwanda Ministry of Health. (2010). Report of the National Mass Drug Administration (MDA) through the Mother and Child Health Week 27-30 April 2010, (April), 1-6.

Sady, H., Al-Mekhlafi, H. M., Mahdy, M. A. K., Lim, Y. A. L., Mahmud, R., \& Surin, J. (2013). Prevalence and Associated Factors of Schistosomiasis among Children in Yemen: Implications for an Effective Control Programme. PLOS Neglected Tropical Diseases, 7(8). http://doi.org/10.1371/journal. pntd.0002377

Shane, H. L., Verani, J. R., Abudho, B., Montgomery, S. P., Blackstock, A. J., Mwinzi, P. N. M., Secor, W. E. (2011). Evaluation of urine CCA assays for detection of Schistosoma mansoni infection in Western Kenya. PLoS Neglected Tropical Diseases, 5(1), 1-7. http:// doi.org/10.1371/journal.pntd.0000951

Sousa-Figueiredo, J. C., Betson, M., Kabatereine, N. B., \& Stothard, J. R. (2013). The Urine Circulating Cathodic Antigen (CCA) Dipstick: A Valid Substitute for Microscopy for Mapping and Point-Of-Care Diagnosis of Intestinal Schistosomiasis. PLoS Neglected Tropical Diseases, 7(1). http://doi.org/10.1371/ journal.pntd.0002008

Teesdale, C. H., Fahringer, K., \& Chitsulo, L. (1985). Egg count variability and sensitivity of a thin smear technique for the diagnosis of Schistosoma mansoni. Transactions of the Royal Society of Tropical Medicine and Hygiene, 79(3), 369-373. http://doi. org/10.1016/0035-9203(85)90384-0

Verani, J. R., Abudho, B., Montgomery, S. P., Mwinzi, P. N. M., Shane, H. L., Butler, S. E., Secor, W. E. (2011). Schistosomiasis among young children in Usoma, Kenya. American Journal of Tropical Medicine and Hygiene, 84(5), 787-791. http://doi.org/10.4269/ ajtmh.2011.10-0685 